\title{
Design of Assembled Systems Based on Conjugated Polyphenylene Derivatives and Carbon Nanohorns
}

\author{
Daniel Iglesias $^{[a],[b]}$, Javier Guerra ${ }^{[a],[c]}$, M. Victoria Gómez ${ }^{[a]}$, Antonio M. Rodríguez ${ }^{[a],[d]}$, Pilar Prieto ${ }^{[a]}$, \\ Ester Vázquez ${ }^{[a]}$, M. Antonia Herrero*[a] \\ Abstract: Promising materials have been designed and fully \\ characterized by an effective interaction between versatile platforms

\section{Introduction} \begin{abstract}
as carbon nanohorns (CNHs) and conjugated molecules based on thiophene derivatives. Easy and non-aggressive methods have been described for the synthesis and purification of the final systems. Oligothiophenephenylvinylene (OTP) systems with different geometries and electron density are coupled to the CNHs. A wide range of characterization techniques confirms the effective interaction between the donor (OTP) and the acceptor $(\mathrm{CNH})$ systems. These hybrid materials show potential on their integration in solar cells devices. Importantly, surface-enhanced Raman spectroscopy (SERS) effects are observed without the presence of any metal surface in the system. Theoretical calculations have been performed in order to study the optimised geometries of the non-covalent interaction between the surface and the organic molecule. Calculations allow us to extract information on the monoelectronic energies of HOMOLUMO orbitals and band gap of different donor systems.
\end{abstract}

Graphene (G) ${ }^{[1]}$ carbon nanotubes $(\mathrm{CNTs})^{[2]}$ and carbon nanohorns $(\mathrm{CNHs})^{[3]}$ are some examples of graphene-based carbon nanomaterials. Since their discovery, G and CNTs are under investigation by many research groups and companies with promising results in many different fields. ${ }^{[4]}$ However, CNHs have caused much less attention even considering that their large surface area, high porosity and semiconducting properties, could afford better results than $\mathrm{G}$ or CNTs. CNHs consist of single graphene sheets rolled up in horn-shape tubules $(2-5 \mathrm{~nm}$ in diameter and $30-50 \mathrm{~nm}$ in length) that are associated in globular clusters around $100 \mathrm{~nm}$. Moreover, high purity $\mathrm{CNHs}$ can be produced with high-yield in the absence of metals, allowing their use in medicinal chemistry. ${ }^{[5]}$ Even though medicinal chemistry, biosensors or gas storage are areas where $\mathrm{CNHs}$ have been applied, solar energy production is one of the most promising fields for the use of these interesting nanostructures. ${ }^{\left[{ }^{[]}\right.}$In this way we have recently described how the inclusion of $\mathrm{CNHs}$ can increase the efficiency of dye sensitised solar cells (DSSCs) making their construction process more environmentally friendly. ${ }^{[7]}$ This work was preceded by the contributions of Vizuete et al., ${ }^{[8]}$ who presented some DSSCs with fascinating supramolecular systems made of CNHs and a porphyrin, and by Pagona et al., ${ }^{[9]}$ who designed systems based on CNHs covalently bound to a porphyrin. The efficiencies reported up to now are very low to be commercialized but these first approaches awarded us with highly promising results, encouraging our research towards more efficient devices.

The underlying motivation for this work is the paired realization that $\mathrm{CNH}$ display outstanding physico-chemical features but are extremely difficult to manipulate or functionalize without destroying their structure. In their pristine forms (as-produced by many companies) most of these carbon nanostructures are completely intractable and insoluble in common solvents. The design of these new structures could provide a powerful means for controlling and modifying $\mathrm{CNH}$-based activity without destroying their inherent properties. Functionalization of graphene-based materials is understood as the introduction of chemical entities in the graphitic walls of the nanomaterials. It can be divided in two groups depending on the nature of the interaction: i) covalent functionalization; and ii) non covalent functionalization. ${ }^{[10]}$ Covalent modification permits a better control of the level of functionalization providing very stable materials, however, the introduction of these covalent bonds distort the vast aromatic system compromising, at some extent, the electronic properties of the nanostructures. On the contrary, non-covalent 
functionalization maintains the structure of the pristine materials intact, preserving their properties.

Dendritic molecules with polyconjugated branches have become particularly attractive materials for their use in organic devices because of their good processability and high-absorption intensity. ${ }^{[11]}$ Interesting optoelectronic applications have been observed in different oligothiophene-based dendrimers with different cores, branching units, or positions of the oligothiophene units. ${ }^{[12]}$ The thiophene-based compounds are easily tunable in a convenient fashion by chemical modification. ${ }^{[13]}$

In this manuscript, we have designed a new series of hybrids, layer-block $\pi$-conjugated dendrons with alternating thienylenevinylene and phenylenevinylene units. ${ }^{[14]}$ Structural modifications of the $\pi$-conjugated thienylenevinylene dendrimers improved the inherent properties and their attractive features for organic solar cells. ${ }^{[15]}$ Thereupon, considering that solar irradiance has its maximum in the visible range, chemical functionalization of $\mathrm{CNH}$ s seems to be a good manner to increase the sunlight absorption and facilitate the separation of excitons. ${ }^{[16]}$ For these reasons, we report a new type of functionalized $\mathrm{CNH}$ with a new family of oligothiophene-phenylenevinylene (OTP) derivatives through non covalent interactions. The functionalization protocol should be able to tune some properties as the light harvesting ability, maintaining at the same time others such as their electronic performance and shape. ${ }^{[17]}$ This family of derivatives has been successfully integrated in solar cells devices with a high efficiency, therefore a separate manuscript has been prepared with a completed study of the efficiency of the different derivatives in solar cells. ${ }^{[18]}$ Promising SERS effects have been observed when the CNHs are attached to the OTP derivatives in the absence of any metal. In the present work, DFT and TDDFT calculations were also performed in order to obtain information on the monoelectronic energies of HOMO-LUMO orbitals and band gap of different OTP donor systems, as well as the optimised geometries of the non-covalent interaction of different OTP species.

\section{Results and Discussion}

To develop these nanocomposites, we first synthesized a family of OTP alternating thienylenevinylene and phenylenevinylene units. Many oligo- or polythiophene derivatives have been described in literature. ${ }^{[17,19]}$ The reported structures typically include alkyl chains that make the compounds soluble in most of the organic solvents. In this regard, very attractive structures were prepared by Patrick et al. anchoring octyl chains and poly(benzyl ether) dendrons leading to the solubilization of a thiophene chain of eleven units. ${ }^{[19 a]}$ Other compounds have been described more recently, using the same solubilizing strategy to prepare organic materials with application in the field of electronic devices. ${ }^{[19 \mathrm{~b}, \mathrm{c}]}$ In our case, we decided to synthesize molecules with different number of thiophene units (six, nine or twelve for DI-3tph, TRI3tph and TETRA-3tph respectively) with a central phenyl core. The substitution pattern of the core permitted the synthesis of molecules with different shapes, these being linear for DI-3tph, star-like for TRI-3tph and cruciform for TETRA-3tph. Scheme 1 shows the synthesis of these compounds. As can be noted, neither alkyl chains nor other solubilizing groups were used. This fact could be thought to be a drawback, however the low solubility of the OTP is actually an advantage for the preparation of the nanocomposites afterwards. The low solubility favours the interaction of OTP with the graphitic walls of the carbon nanostructures.

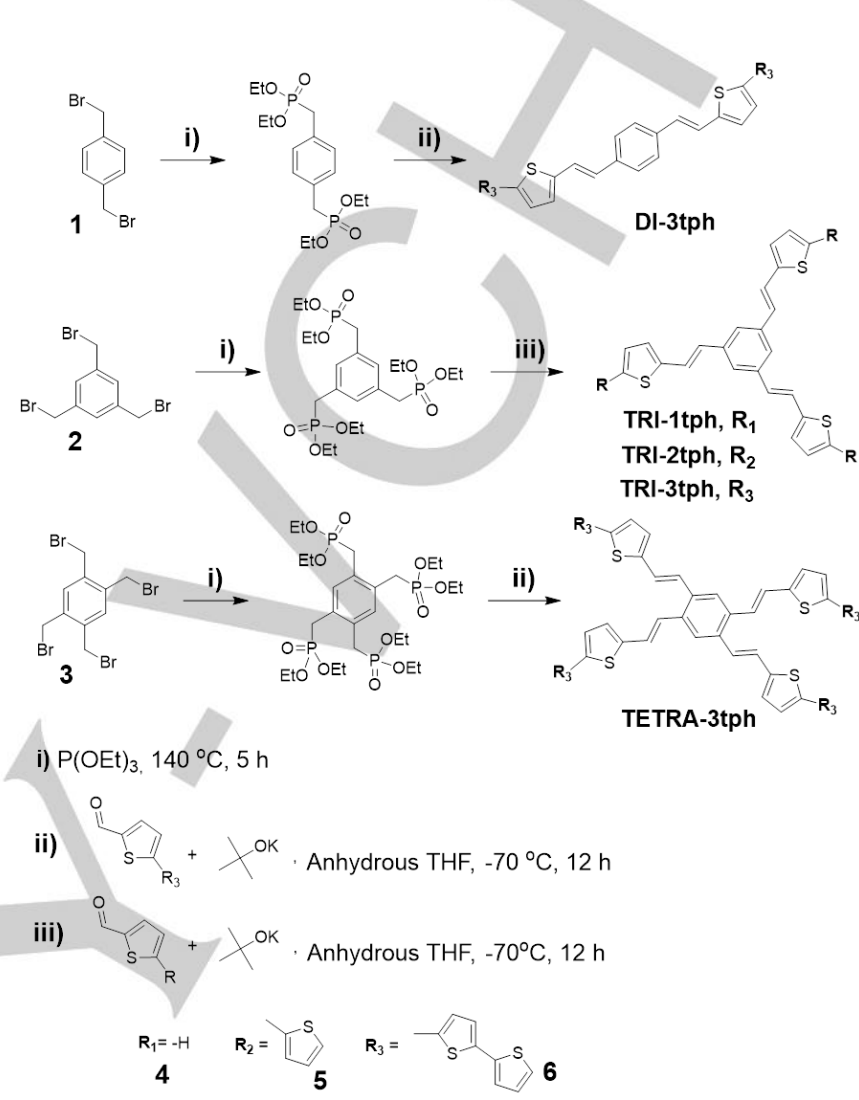

Scheme 1. Synthesis of the organic compounds.

The synthetic protocol applied was reported by Hadad et al. ${ }^{[14]}$ who applied the Horner-Wadsworth-Emmons reaction for the synthesis of oligothiophene-phenylenevinylene dendrimers (Scheme 1). As a proof of the synthetic strategy, firstly we synthesized the TRI-1tph, star-like shape and 3 thiophenes units, this derivative was easily characterized. The protocol resulted to be selective for trans- isomer formation when one thiophene unit was attached to the phenylenevinylene core (TRI-1tph). The retention of the selectivity was also confirmed by the presence of two doublets in the ${ }^{1} \mathrm{H}$-NMR spectrum with a coupling constant around $16 \mathrm{~Hz}$ for TRI-2tph, star-like shape and 6 thiophene units, nonetheless very low solubility of the TRI-3tph did not allow the proper assignment of this derivative. No completed assignment of similar systems was observed in other studies. ${ }^{[19 d, 20]}$ The MALDITOF confirmed unequivocally the presence of the final derivatives in all the cases (Figure S1-S5). The infrared spectra revealed no presence of the corresponding aldehyde due to the absence of a very intense band at around $1660 \mathrm{~cm}^{-1}$ which shows up in the IR of the corresponding starting material (Figure S6 and S7). 


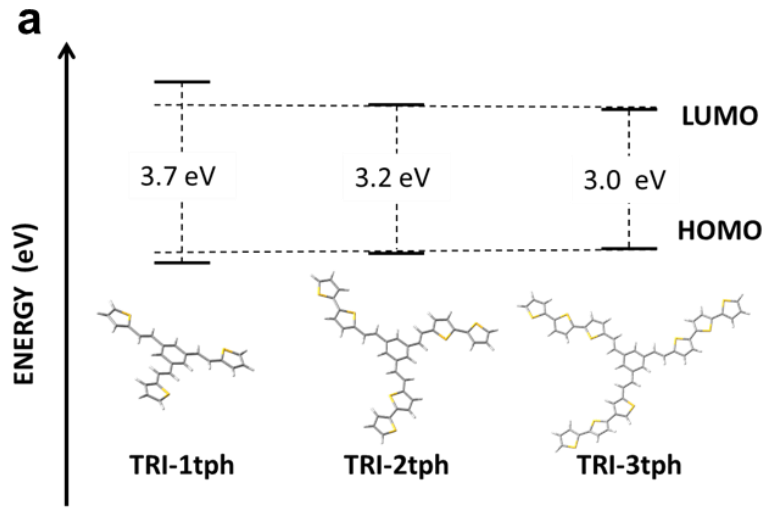

b

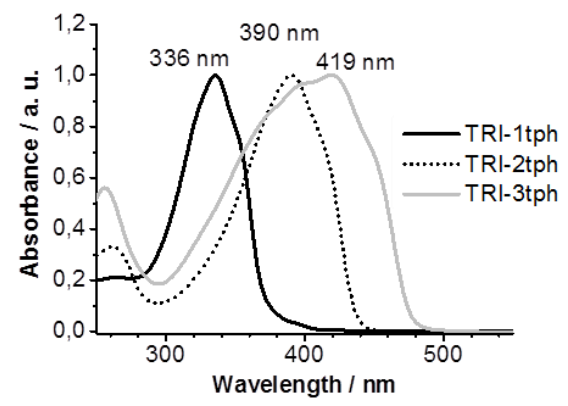

Figure 1. (a) Calculated band-gap and geometry for the tri-substituted derivatives at B3LYP/6-31G (d)*; (b) absorbance spectra of tri-substituted derivatives $\left(\sim 10^{-5} \mathrm{M}\right.$ in $\left.\mathrm{CHCl}_{3}, \mathrm{RT}\right)$.

The synthesis of the trisubstituted compounds also confirmed the hypothesis that the HOMO-LUMO band gap of this kind of compounds can be engineered varying the length of the heterocyclic chain. B3LYP/6-31G(d)* computational calculations were carried out in order to study both the geometry and the HOMO-LUMO topology. Figure 1a shows that all compounds display a planar geometry with a slight bending between each thiophene unit. Moreover, the band gap ranges from $3.7 \mathrm{eV}$ for the shorter one to $3.0 \mathrm{eV}$ for the longest one. Band-gap energy is a decisive parameter which determines the wavelength of absorbance, the lower the band-gap energy the higher the wavelength of absorbance.

Table 1. $\lambda \max _{a b s}$ for compounds TRI-1tph, TRI-2tph and TRI-3tph computed using TD-DFT calculations at $\mathrm{m06}-2 \mathrm{X} / 6-311+\mathrm{G}(2 \mathrm{~d}, 2 \mathrm{p}) / / \mathrm{m} 06-2 \mathrm{X} / 6-31 \mathrm{G}(\mathrm{d})$ level of theory.

\begin{tabular}{cccc}
\hline Compound & TRI-1tph & TRl-2tph & TRI-3tph \\
\hline Experimental $\boldsymbol{\lambda}_{\max }(\mathrm{nm})$ & 336 & 392 & 419 \\
\hline Theoretical $\boldsymbol{\lambda}_{\max }(\mathrm{nm})$ & 337 & 389 & 416 \\
\hline
\end{tabular}

Furthermore, we calculate the UV-Vis absorption spectra of these compounds. The calculated $\lambda_{\max }$ values are collected in Table 1 (see spectra in Electronic Supplementary Information, Figure S8S10). The electronic spectra have also been calculated in chloroform solution using the conductor-like polarizable continuum model (CPCM) ${ }^{[21]}$ and the time dependent density functional theory (TD-DFT) approach. ${ }^{[22]}$ We have used the M06$2 X^{[23]}$ meta-exchange functional. The choice of this functional has been based on the accurate results obtained in the calculation of systems with high spatial orbital overlap, which are even better than those provided by the more widely used CAM-B3LYP.

Computational results are in total agreement with the experimental spectra. The maximum of absorbance is shifted to higher wavelengths when increasing the number of thiophene units (Figure 1b). This fact confirms the power of computational chemistry as a predictive tool.

Once we confirmed the good response of the synthetic protocol when terthienyl units were linked to the phenylenevinylene core, we moved to the synthesis of DI-3tph and TETRA-3tph following the described strategy but changing the substitution pattern of the core (Scheme 1). Both products were obtained with high yields. A detailed analysis of every ${ }^{1} \mathrm{H}$ and ${ }^{13} \mathrm{C}$ NMR data for compounds with three thiophene units cannot be found in the literature, ${ }^{19 \mathrm{~d}, 20]}$ probably due to the overlapped peaks and the low solubility of these molecules. Here, we assigned proton and carbon signals through a set of $1 \mathrm{D}$ and $2 \mathrm{D}$ experiments. The whole description of the thorough NMR study performed is included in the supporting information with the corresponding figures (Figure S13-S16). Table S1 and S2 show the ${ }^{1} \mathrm{H}$ and ${ }^{13} \mathrm{C}$ NMR data for DI-3tph and TETRA-3tph respectively.

Once again, IR spectroscopy and MALDI-TOF MS spectrometry confirmed the chemical structure of the derivates (Figures S6-S7 and S3-S5).

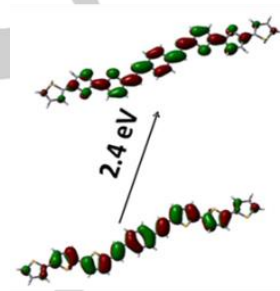

DI-3tph

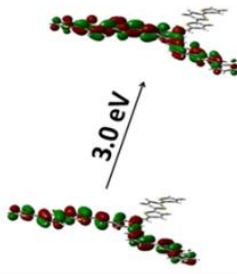

TRI-3tph

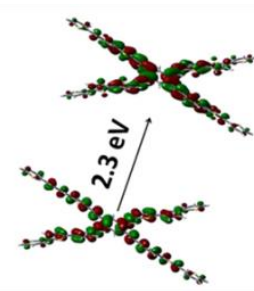

TETRA-3tph
Figure 2. Calculated HOMO-LUMO band-gap and geometry of DI-3tph, TRI-3tph and TETRA-3tph at B3LYP/6-31G(d) theory level.

Figure 2 shows calculated HOMO-LUMO band-gap and geometry of the OTP derivatives DI-3tph, TRI-3tph and TETRA3tph. On one hand, these results provide information about the planarity of DI-3tph that could favour the $\pi-\pi$ stacking interaction with the consequent reduction of solubility. On the other hand, the steric hindrance between the vinyl protons induces the torsion of the thienyl-vinylene branches in the cruciform structure TETRA3tph. Moreover the computational results clearly show that the HOMO-LUMO band-gap is extremely dependant on the substitution pattern, for these reasons, DI-3tph and TETRA-3tph have a lower band-gap than TRI-3tph. This fact suggests that the blocked conjugation of the $\pi$ cloud due to the meta-like substitution prevents lowering of the band-gap.

Table 2. $\lambda \max _{a b s}$ for compounds DI-3tph, TRI-3tph and TETRA-3tph computed using TD-DFT calculations at m06-2X/6-311+G(2d,2p)//m06-2X/6$31 \mathrm{G}(\mathrm{d})$ level of theory.

\begin{tabular}{cccc}
\hline Compound & DI-3tph & TRI-3tph & TETRA-3tph \\
\hline Experimental $\boldsymbol{\lambda}_{\max }(\mathrm{nm})$ & 356,450 & 419 & 439 \\
\hline Theoretical $\boldsymbol{\lambda}_{\max }(\mathrm{nm})$ & 343,463 & 416 & 434 \\
\hline
\end{tabular}


In this particular case, computational modelling fits also well with experimental data since TRI-3tph, DI-3tph and TETRA-3tph are yellow, orange and red respectively (Figure S17). This visual observation was confirmed by UV-Vis spectroscopy theoretical and experimentally (Table 2, Figure 3 and Figure S10- S12)

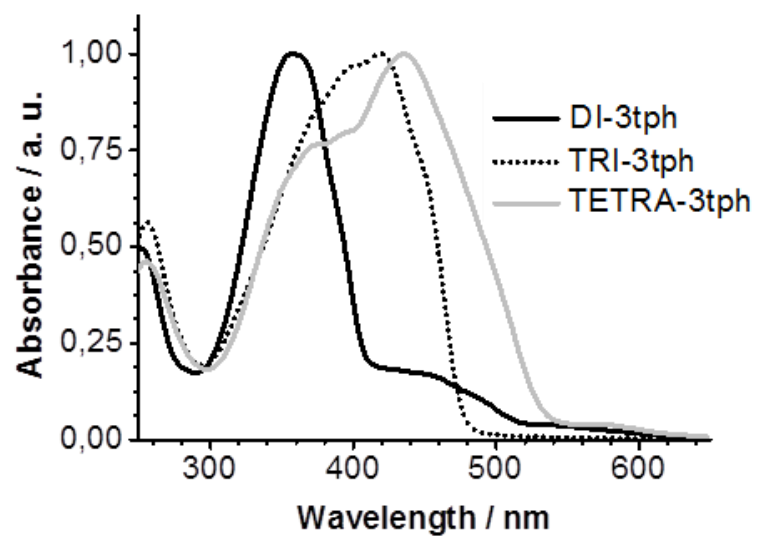

Figure 3. Absorbance spectra of OTP derivatives $\left(\sim 10^{-5} \mathrm{M}\right.$, in $\left.\mathrm{CHCl}_{3}, \mathrm{RT}\right)$.

Figure 3 shows the UV-Vis spectra of the aforementioned species. DI-3tph with two peaks at 356 and $450 \mathrm{~nm}$ presents an analogous profile to similar compounds described in literature. ${ }^{[24]}$ The same work describes the presence of some small humps as seen in TRI-3tph (at around 375 and $400 \mathrm{~nm}$ ) that may arise from small absorption bands overlapped by the maximum at $419 \mathrm{~nm}$. Finally, TETRA-3tph displays its maximum of absorbance at $439 \mathrm{~nm}$ and a broad shoulder at $372 \mathrm{~nm}$. Very similar compounds described in literature but with alkyl chains did not displayed any shoulder like the one we saw for the latter compound. ${ }^{[19 b]}$ This fact led us to attribute the presence of the shoulder to supramolecular $\pi-\pi$ interactions.

\section{Functionalization of CNHs with oligothiophene derivatives}

Three different functionalized nanohorns were synthesized by non-covalent interaction of $p$-CNHs with DI-3tph (CNHs-DI3tph); TRI-3tph (CNHs-TRI-3tph); and TETRA-3tph (CNHsTETRA-3tph).

The nanocomposites were prepared as presented in Scheme 2. Pristine CNHs were mixed with the thiophene derivatives, sonicated and stirred. Afterwards the reaction mixture was filtrated with different solvents. The final derivatives were isolated and fully characterized using different techniques including thermogravimetric analysis (TGA), UV-Vis spectroscopy, Raman spectroscopy, fluorescence spectroscopy and transmission electron microscopy (TEM).

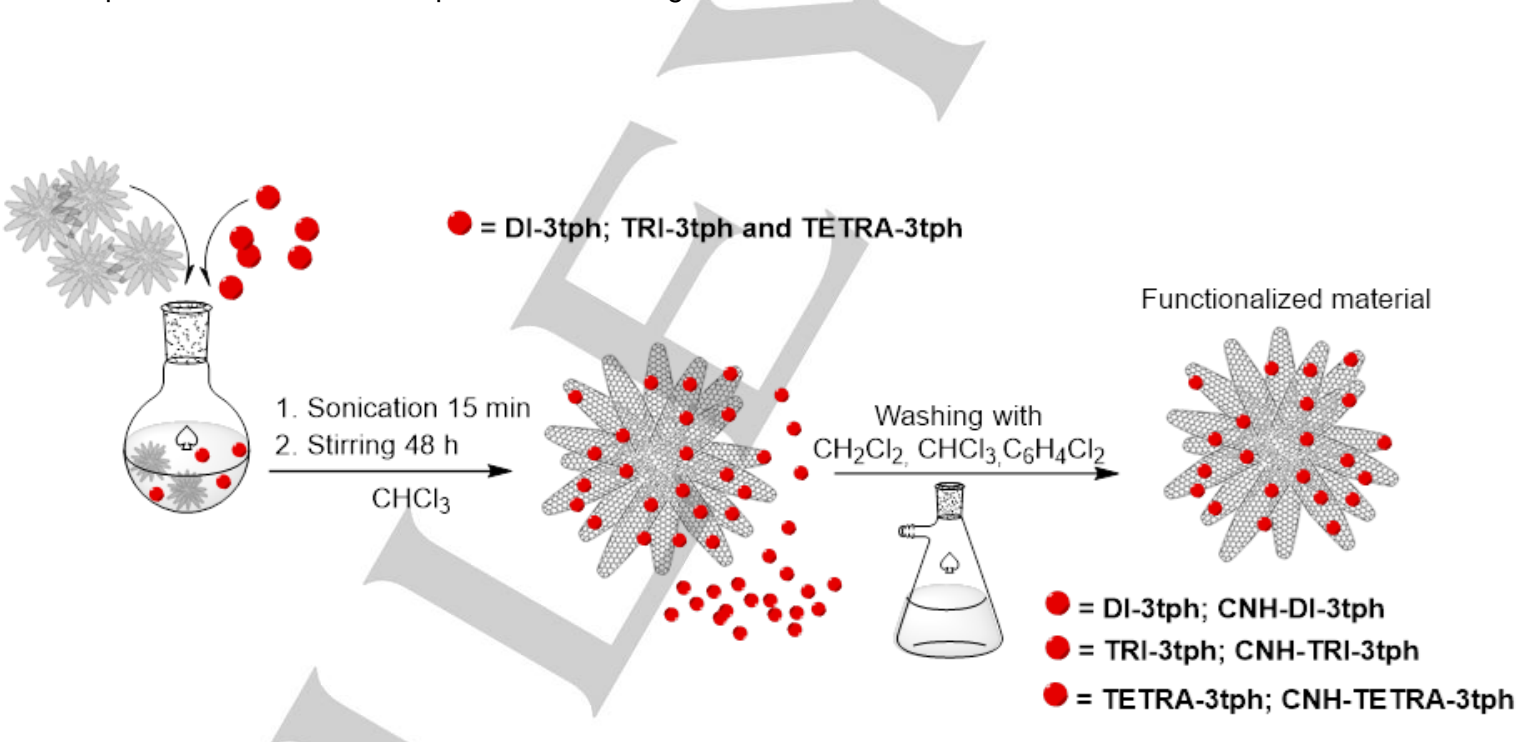

Scheme 2. Schematic synthesis of the nanocomposites (CNHs-DI-3tph, CNH-TRI-3tph and CNHs-TETRA-3tph. 


\section{Thermogravimetric analysis}

The stability of $\boldsymbol{p}$-CNHs at high temperature allows the analysis of these materials using TGA. Figure $\mathbf{4 b}$ displays the thermograms of the prepared nanocomposites and the pristine material under nitrogen atmosphere. Pristine CNHs are very stable up to $900{ }^{\circ} \mathrm{C}$ while CNHs-DI-3tph, CNHs-TRI-3tph and CNHs-TETRA-3tph start to decompose at lower temperatures $\left(200{ }^{\circ} \mathrm{C}\right.$ for CNHs-TRI-3tph and $\sim 400^{\circ} \mathrm{C}$ for while CNHs-DI-3tph and CNHs-TETRA-3tph), afterwards they are stable up to $\sim 700$ ${ }^{\circ} \mathrm{C}$, when a second decomposing step takes place. This lower stability observed for the CNHs-TRI-3tph, took also place for the dendron alone Tri-3tph (Figure S4a).

\section{a}
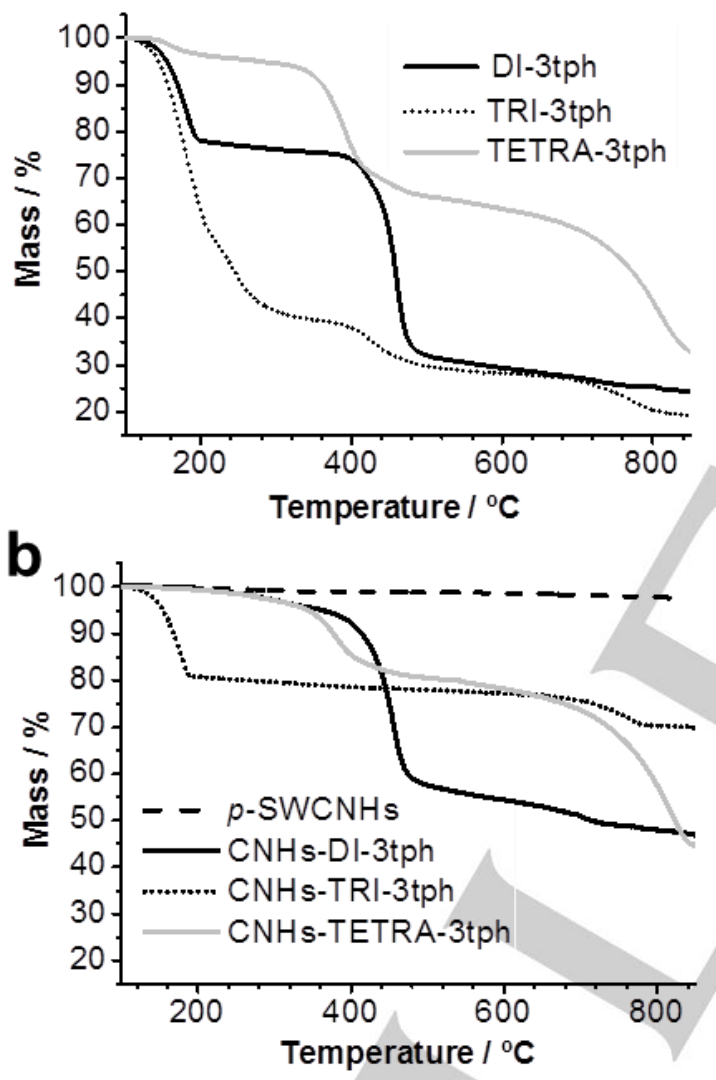

Figure 4. Thermograms under $\mathrm{N}_{2}$ of (a) DI-3tph, TRI-3tph and TETRA-3tph; (b) the nanocomposites CNHs-DI-3tph, CNHs-TRI-3tph and CNHs-TETRA-3tph.
The degree of functionalization was calculated by TGA experiments under nitrogen atmosphere. A weight loss of $45 \%$ was observed for CNHs-DI-3tph, corresponding to $732 \mu \mathrm{mol}$ of organic compound per gram of CNHs. A lower degree of functionalization was obtained for CNHs-TRI-3tph (30\%, 335 $\mu \mathrm{mol} \mathrm{g}^{-1}$ ) and CNHs-TETRA-3tph (56\%, $\left.480 \mu \mathrm{mol} \mathrm{g}^{-1}\right)$. The different levels of functionalization of the nanocomposites may have an explanation on the different solubility and shape of the organic molecules, leading the latter to different kind of interaction with $\mathrm{CNHs}$. A detailed study of these supramolecular interactions is included in the computational part. Besides, the different distribution of the frontier orbitals along TRI-3tph compared with the other two compounds (Figure 2) leads us to expect a different behaviour when interacting with $\mathrm{CNHs}$. In this regard, the distribution of the frontier orbitals have been recently proven to be a key factor for the supramolecular interaction of organic molecules with $\mathrm{CNH}$ s by Muñiz and co-workers. ${ }^{[25]}$ Furthermore, the thermograms give us information about the thermal stability of these compounds. In this case, CNHs-DI-3tph and CNHsTETRA-3tph are stable up to $400{ }^{\circ} \mathrm{C}$ which make them good candidates for their implantation in solar cell devices.

\section{Computational modelling of the nanocomposites}

In order to complete our understanding of how these molecules interact with the $\mathrm{CNHs}$, we also performed the computational analysis of the mentioned systems. Although there are many computational works on carbon nanostructures, such as fullerenes, CNTs and $\mathrm{G}^{\left[{ }^{[26]}\right.}$ studies on $\mathrm{CNH}$ s remain scarce in the literature, mostly due to their higher complexity. Reproduction of a complete nanohorn is difficult due to the high size of the system to model; its size makes it also a problem of high computational cost, reaching at some point the upper limit on the modelling capabilities of DFT methods. As far as our knowledge is concerned, all reports in the literature study of molecular interactions with $\mathrm{CNHs}$ with the use of one "nanohorn-arm" ${ }^{[26] ~ I n ~}$ this work, we used a limited nanohorn model of $217 \mathrm{C}$ terminated by 19 hydrogen atoms and having a diameter of $13.5 \mathrm{~A}^{\circ}$ at the wide end, as described in the literature. ${ }^{[27]}$ These results were then treated as a pre-optimization input to a full DFT calculation taking into account Grimme's DFT-D scheme to evaluate the dispersion forces. ${ }^{[28]}$ Our results show that the interaction of the molecules is preferably done via the wall surface of the nanohorns through a series intramolecular interaction of the aromatic moiety of the molecules and the carbon nanohorn. 


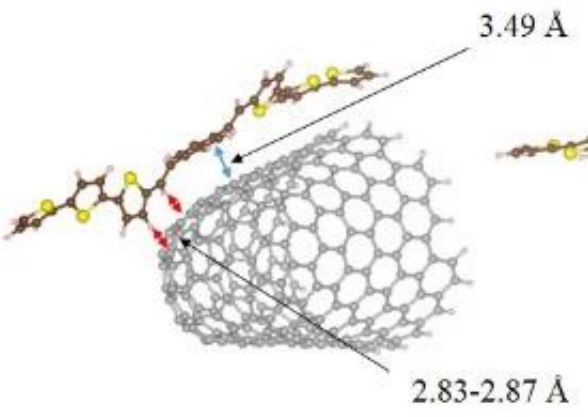

(a)

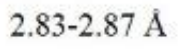

CNHs-DI-3tph

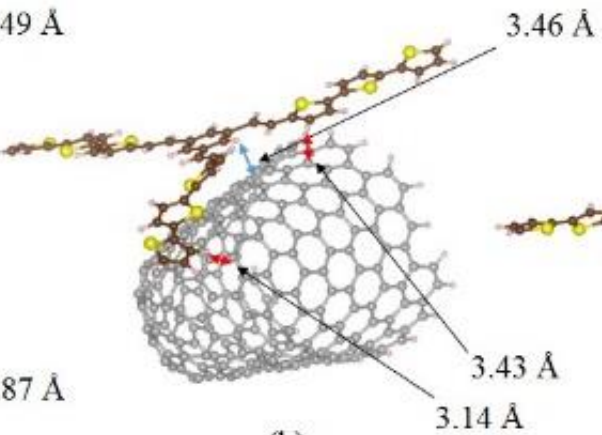

(b)

$3.14 \AA$

CNHs-TRI-3tph

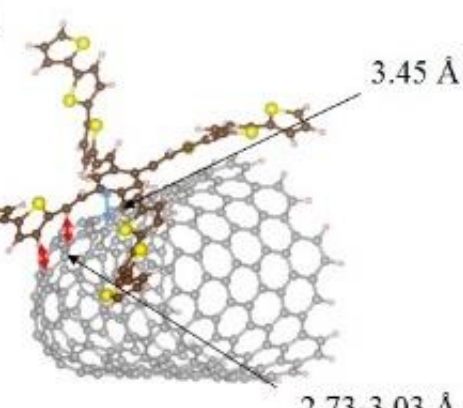

(c)

2.73-3.03 $\AA$

CNHs-TETRA-3tph

Figure 5. Supramolecular systems of the DI-3tph, TRI-3-tph and TETRA-3tph (the colour of the CNH moiety has been changed for visualization purposes) computed at B97D3/6-31G(d,p) level of theory.

Structurally speaking, we can address the different behaviour in the aggregation form of these compounds. In CNHs-TRI-3tph the $\pi-\pi$ stacking between TRI-3tph and the nanohorn $(3.1 \AA)$ are the non-covalent forces directing the self-assembly (blue interactions in Figure 5). Contrary, in CNHs-DI-3tph and CNHs-TETRA-3tph, the $\mathrm{CH}-\pi$ interaction play an important role. In both case, the phenylenevinylene core adopt a torsion structure in order to maximize the $\mathrm{CH}-\pi$ interaction between the proton of the thiophene ring and the $\mathrm{CNHs}(\sim 3 \AA)$, as well as, the interaction between the olefin proton and the $\mathrm{CNH}$ s $(\sim 2.9 \AA$ ) (red marked in Figure 5). We suggest that the existence of interaction $\mathrm{CH}$ - $\pi$ could justify the increased stability of these aggregates.

Although the structural features are well defined with the general DFT-D methods, we found out an overbinding on the adsorption energies above to that expected on these systems. We know studying supramolecular interactions is not trivial and its computational study needs to address the Basis Set Superposition Error (BSSE), which could explain the overbinding effect. However, further refinement with the BSSE correction method at a higher level of theory ${ }^{[29]}$ revealed too expensive computationally for these systems. Further work will aim to study these systems through other methodologies to circumvent these problems.

\section{Photophysical properties}

The light harvesting ability of the nanocomposites was investigated by UV-Vis spectroscopy. This is a main technique for the characterization of these materials since sunlight collection is the first step involved in solar cells devices. ${ }^{[30]}$

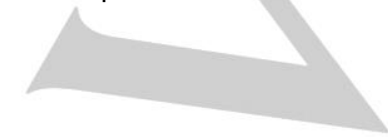

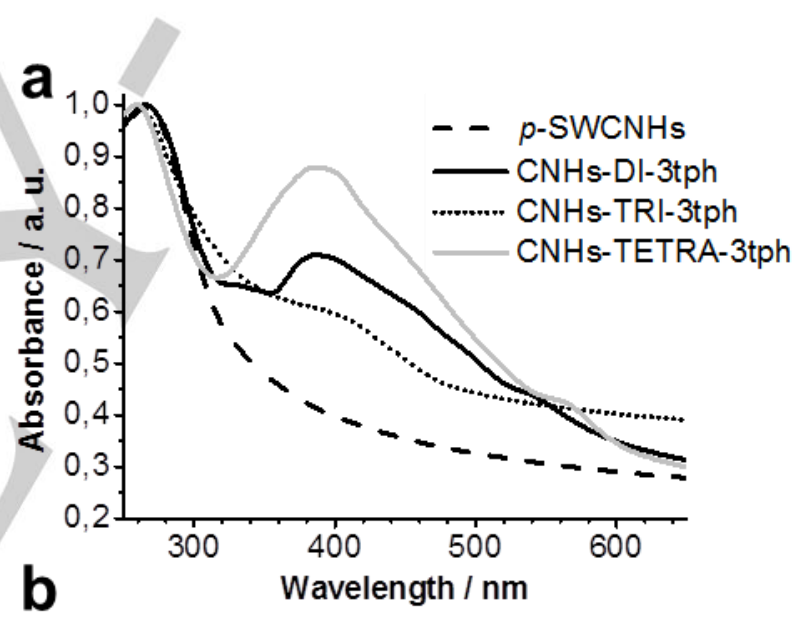

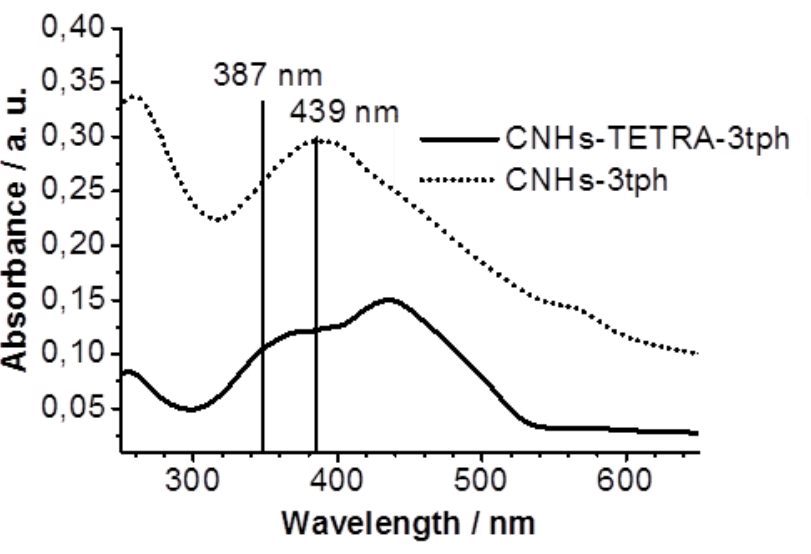

Figure 6. (a) UV-Visible spectra of the nanocomposites $\left(0.01 \mathrm{mg} \mathrm{mL}^{-1}\right.$, in $\mathrm{CHCl}_{3}$, $\mathrm{RT})$ and $\mathrm{p}-\mathrm{CNHs}(\mathrm{b})$ UV-Vis spectra of CNHs-TETRA-3tph and TETRA-3tph $\left(\mathrm{CHCl}_{3}, \mathrm{RT}\right)$.

Figure 6 shows the absorbance spectra of $p$-CNHs and the nanocomposites. All the nanocomposites displayed an absorbance band that confirms the presence of the corresponding OTP plus the featureless absorbance of $\mathrm{CNHs}$ which ends up with 
an intense peak around $\sim 263 \mathrm{~nm}$. The bands related to the organic compounds suffered dramatic modifications likely due to the interactions with the graphitic walls of the nanostructures. In the case of CNHs-TETRA-3tph both the peak and the broad band (at 372 and $439 \mathrm{~nm}$ ) evolved to a single peak at $386 \mathrm{~nm}$ (Figure $6 b)$. We postulate that the blue shift of the peak could be due to the stabilization of the $\pi$ cloud of TETRA-3tph for the interaction with the nanostructure that additionally disrupts formation of TETRA-3tph aggregates with the consequence disappearing of the shoulder. Similar statement can be done for CNHs-DI-3tph that shows a peak shifted to $388 \mathrm{~nm}$ and no presence of any extra peak. The case of CNHs-TRI-3tph is slightly different since the peak related to the organic molecule is overlapped by the absorbance of the CNHs, however the shoulder at $419 \mathrm{~nm}$ together with other analysis unambiguously confirms it presence. Therefore, UV-visible spectra show clearly that there is an effective interaction between the thiophene derivatives and $\mathrm{CNHs}$ (Figure 6b, S20 and S21).

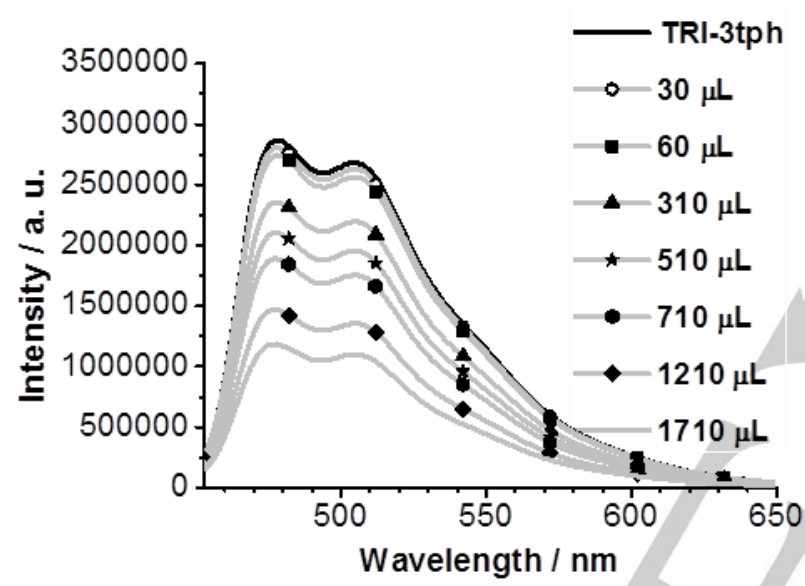

Figure 7. Fluorescence spectra of TRI-3tph upon addition of CNHs, $\lambda_{\mathrm{ex}}=419$ $\mathrm{nm}$. The concentration of OTP was constant in all the experiments. DMF was used as solvent to avoid fluctuations in the concentrations that typically take place with low boiling point solvents.

Moreover, the intensity of the fluorescence is decreased by the addition of $\mathrm{CNH}$ in every derivative, providing another proof of the interaction (Figure 7, Figure S22 and S23). The experiment was designed in such a way that the concentration of the organic molecule is constant during the experiment (see Experimental section). This quenching of fluorescence was observed for all the nanocomposites CNHs-DI-3tph, CNHs-TRI-3tph and CNHsTETRA-3tph (Figure 7, Figure S22 and S23). Similar behaviour was reported for a different type of hybrid materials made of $\mathrm{CNHs}$ and a pyrene/porphyrin derivative as a consequence of the electro and/or energy transfer between the organic molecule and CNHs. ${ }^{[31]}$

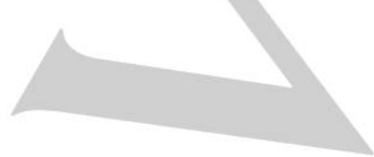

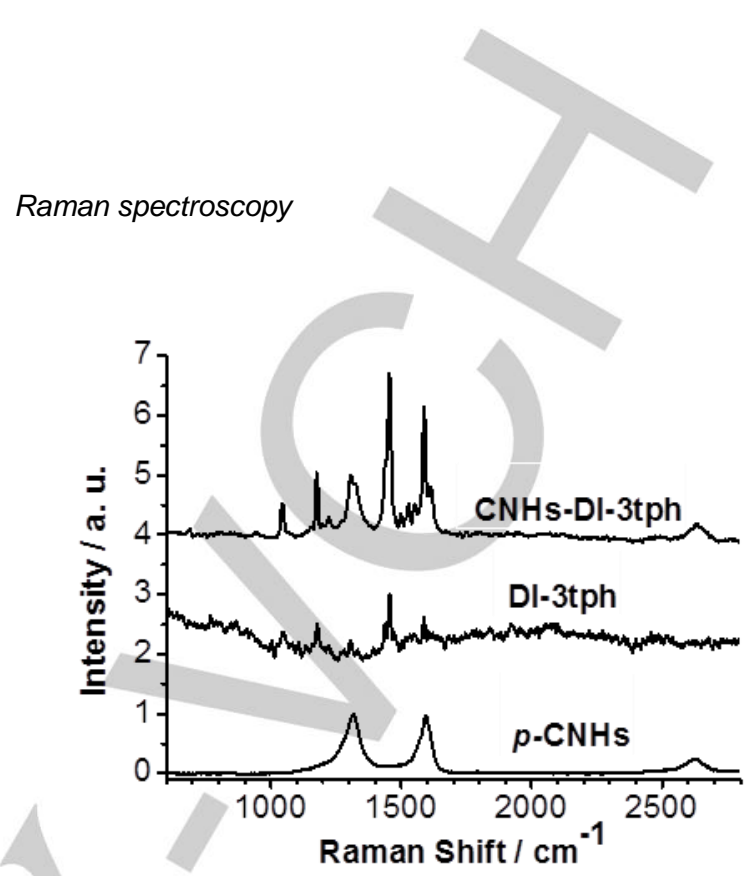

Figure 8. Raman spectra of $\boldsymbol{p}$-CNHs, DI-3tph from glass substrate and CNHs-DI3tph (Laser: $633 \mathrm{~nm}$ ).

The Raman spectroscopy is a powerful technique for the characterization of these derivatives. Raman spectra of the pristine CNHs, organic molecules (DI-3tph, TRI-3tph and TETRA-3tph) and the final derivatives (CNHs-DI-3tph, CNHsTRI-3tph and CNHs-TETRA-3tph) are reported in the Figures 8, S24 and S25. A typical Raman spectrum of the pristine CNHs exhibits two prominent bands, a disorder-induced mode (D-band) at $1320 \mathrm{~cm}^{-1}$ and a G-band at $1590 \mathrm{~cm}^{-1}$ and a smaller peak at $2900 \mathrm{~cm}^{-1}$, this band can be related to the presence of defects. The three different organic molecules synthesized (DI-3tph, TRI3tph and TETRA-3tph) show low intensity when the Raman is taken from a simple deposition of these molecule on a glass surface.

Figure 8 illustrates the dramatic change that occurs when the photoexcited organic molecule (DI-3tph) transfer its energy to the $\mathrm{CNH}$ s and does not emit fluorescent light. ${ }^{[31]}$ It can be observed a well-defined Raman spectrum of the DI-3tph when it is interacting with the CNHs. Therefore, the Raman of CNHs-DI-3tph represents a surface Raman spectrum with resonance enhancement of the adsorbate (DI-3tph) combined with the typical signal of the $\mathrm{CNH}$. Carbon does not support electromagnetic enhancement, so surface Raman on carbon is guaranteed of a chemical enhancement that is based on a charge transfer between the molecule and the substrate. ${ }^{[32]}$ This molecule signal enhancement allows us a better characterization of the final derivatives even with a small amount of the desired molecule. 
To the best of our knowledge, this is the first case in the literature, in which $\mathrm{CNH}$ s have shown an intensification of the Raman spectra of an organic molecule. Single layer graphene sheet has been studied previously as a platform for surface-enhanced Raman Spectroscopy (SERS). ${ }^{[32-33]}$ Theoretical studies and some samples on the literature confirm the possible application of the carbon allotropes surfaces in the role of molecule-surface vibrational coupling in SERS. ${ }^{[34]}$ This is a preliminary result that shows a high resolution of the Raman spectra using these new derivatives based on CNHs. Previously, other groups had discussed and proven that it is very important not only the surface but also the distance and the type of interaction between the molecule and the surface for a chemical enhancement. ${ }^{[35]}$ Therefore, further studies will be published based on the application of CNHs in SERS with different derivatives of CNHs. For this study a new family of functionalized $\mathrm{CNHs}$ has been prepared varying important parameters such as the distance or the nature of the functionalization. Among the three derivatives studied here, the Raman spectra of the derivatives CNHs-DI-3tph and CNHs-TETRA-3tph display a higher intensification than CNHs-TRI-3tph. Previously, it has been discussed that computational studies corroborated a different interaction and behaviour of these two derivatives compared to the CNHs-TRI3tph, therefore it is clear that the nature of the interaction and the distance are main keys to take into account in the design of these systems.

\section{Transmission electron microscopy}

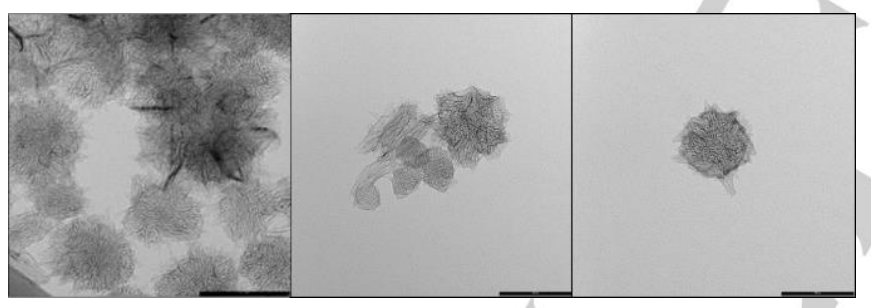

Figure 9. TEM images of $\boldsymbol{p}$-CNHs (left) and CNHs-TRI-3tph (center, right) Scale bar $100 \mathrm{~nm}$.

The different derivatives were investigated by TEM. Typical images are shown as an example in Figure $\mathbf{9}$ for the CNHs-TRI3tph, indicating that the unique structure of $\mathrm{CNHs}$ as well as their spherical aggregates are preserved after the functionalization. The preservation of the graphitic structure likely imply the preservation of the electronic properties in agreement with our initial thoughts and other works reported in literature. ${ }^{[36]}$

\section{Conclusion}

Three interesting new systems made of $\mathrm{CNHs}$ and OTP derivatives with linear, star and cruciform shape have been designed and fully characterized. A special emphasis has been devoted shedding light on the nature of the interaction between the donor and acceptor system. The effective interaction between the organic molecule and the $\mathrm{CNH}$ s has been clearly ascertained by means of several techniques. The synthetic strategy allows us to tune the platform with the corresponding molecule for the desired application. The assembled systems have been successfully applied for the design of dye synthesized solar cells. . It was measured that the terthienyl dye with the largest conjugation deposited on $\mathrm{CNH}$ increases as additive the performance of an analogous $\mathrm{TiO}_{2}$ cell with an efficiency up to $6.24 \%$. Raman spectra point out to promising results in SERS. It was observed an important enhancement of the Raman signal of the terthienyl derivative for the synthesis of these new derivatives. The applicability of these hybrid materials in this field will be reported somewhere else. Therefore, a rational design make possible the combination of an attractive platform such as $\mathrm{CNHs}$ and a versatile molecule widening their range of applications.

\section{Experimental Section}

UV-Vis spectra were recorded on a Varian Cary 5000 spectrophotometer using $1 \mathrm{~cm}$ path length quartz cuvettes. Fluorescence measurements were carried out on a Cary Eclipse Fluorescence spectrophotometer using $1 \mathrm{~cm}$ quartz path length cuvettes. Thermograms were recorded on a thermogravimetric analyzer Q50 (TA Instruments). The analyses were done under $\mathrm{N}_{2}$ from $100{ }^{\circ} \mathrm{C}$ to $900{ }^{\circ} \mathrm{C}$ using a $10 \stackrel{\circ}{\circ} \mathrm{C} / \mathrm{min}$ ramp. $633 \mathrm{~nm}$ laser was used to collect Raman spectra on samples deposited on glass substrates using an Invia Renishaw microspectrometer. For TEM imaging, a concentrated dispersion of the sample were dropcasted on a copper grid ( $3.00 \mathrm{~mm}, 200$ mesh, coated with carbon film), after evaporation of the solvent under vacuum the inspection of the samples was done on a Philips EM 208 microscope operating at $100 \mathrm{kV}$. MALDI-TOF mass spectra were registered in a MALDI-TOF Bruker, autoflex II TOF/TOF. The analysis were done using positive detection mode and dithranol was added as matrix. The NMR experiments for DI-3thp were carried out using a Bruker Advance III operating at $600 \mathrm{MHz}$ for ${ }^{1} \mathrm{H}-\mathrm{NMR}$ and at $150 \mathrm{MHz}$ for ${ }^{13} \mathrm{C}$ NMR experiments. For the analysis of TETRA-3tph, a $500 \mathrm{MHz}$ (Varian, Inova) for ${ }^{1} \mathrm{H}-\mathrm{NMR}$ and at $100 \mathrm{MHz}$ for ${ }^{13} \mathrm{C}$ NMR was used. A $400 \mathrm{MHz}$ (Varian, VNMRS) was used for the study of TRI-1tph and TRI-2tph. The $600 \mathrm{MHz}$ spectrometer was equipped with a cryogenic probe which can significantly increase the $\mathrm{S} / \mathrm{N}$ ratio of NMR spectroscopy, ${ }^{[37]}$ and make possible to study samples that aggregate at elevated concentration. All 1D and 2D NMR experiments (gCOSY, gTOCSY, gHSQC, gHMBC) were performed at $298 \mathrm{~K}$ using standard pulse sequences from Agilent and Bruker libraries. $\mathrm{CD}_{3} \mathrm{OD}$ was the solvent used for DI-3tph and TETRA3tph whilst $\mathrm{CDCl} 3$ was used for TRI-1tph and TRI-2tph. MestreNova (v. 10.0) was used for data processing.

General protocol for the synthesis of oligothiophenephenylvinylene (TRI-1tph, TRI-2tph, TRI-3tph, DI-3tph, TERTRA-3tph): In a typical experiment, under a dry and inert atmosphere, $t \mathrm{BuOK}$ (9 eq) was added to a solution of the corresponding aldehyde $(\mathbf{4}, \mathbf{5}$ or $\mathbf{6})(1.1 \mathrm{eq})$ and the (diethoxyphosphorylmethyl)benzene (1, 2 or 3 ) (1 eq) in anhydrous THF 
$(20 \mathrm{~mL})$ at $-70^{\circ} \mathrm{C}$. The reaction mixture was stirred for $12 \mathrm{~h}$ at $-70^{\circ} \mathrm{C}$. Then, the crude was warmed up to room temperature and the solvent eliminated under reduced pressure. The crude was dispersed in brine solution (50 $\mathrm{mL}$ ) and the resulting dispersion was filtered and washed with brine solution $(200 \mathrm{~mL})$ and distilled $\mathrm{H}_{2} \mathrm{O}(500 \mathrm{~mL})$. The final product was dried under high vacuum.

TRI-1tph: Pale yellow solid (97\%). ${ }^{1} \mathrm{H}$ NMR $\left(400 \mathrm{MHz}, \mathrm{CDCl}_{3}, \mathrm{ppm}\right): \delta=$ 7.46 (s, 3H, Ar-H), 7.32 (d, $J=16.2 \mathrm{~Hz}, 3 \mathrm{H}, \mathrm{H}-1$ vinyl), 7.23 (d, $J=5 \mathrm{~Hz}$, $3 \mathrm{H}, \mathrm{H}-3 \mathrm{tph}$ ), 7.11 (d, $J=3.7 \mathrm{~Hz}, 3 \mathrm{H}, \mathrm{H}-5 \mathrm{tph}$ ), 7.03 (dd, $3 \mathrm{H}, J=5$ and 3.7 $\mathrm{Hz}, \mathrm{H}-4 \mathrm{tph}), 6.95$ (d, $J=16.2 \mathrm{~Hz}, 3 \mathrm{H}, \mathrm{H}-2$ vinyl). FTIR $(\mathrm{KBr}): v\left(\mathrm{~cm}^{-1}\right)=$ 3095, 1623, 1584, 1041 957, 836, 806, 700, 542, 497. MS (MALDI-TOF) C24H18S3. Calc. 402.59, found $401.90[\mathrm{M}+]$.

TRI-2tph: Yellow solid (96\%). ${ }^{1} \mathrm{H}$ NMR $\left(400 \mathrm{MHz}, \mathrm{CDCl}_{3}, \mathrm{ppm}\right) \delta: 7.44$ (s, $3 \mathrm{H}, \mathrm{Ar}-\mathrm{H}$ ), 7.26 (d, $J=16 \mathrm{~Hz}, 3 \mathrm{H}, \mathrm{H}-1$ vinyl), 7.25 (d, $J=3.7 \mathrm{~Hz}, 3 \mathrm{H}$, tph), 7.22 (d, $J=3.7 \mathrm{~Hz}, 3 \mathrm{H}, \mathrm{tph}$ ), 7.11 (d, $J=3.7 \mathrm{~Hz}, 3 \mathrm{H}, \mathrm{tph}$ ), 7.04 (dd, $J=3.5$ and $4 \mathrm{~Hz}, 3 \mathrm{H}, \mathrm{tph}), 7.00(\mathrm{~d}, J=3.5 \mathrm{~Hz}, 3 \mathrm{H}, \mathrm{tph}), 6.90(\mathrm{~d}, J=16 \mathrm{~Hz}, 3 \mathrm{H}, \mathrm{H}-$ 2 vinyl). FTIR $(\mathrm{KBr}) v\left(\mathrm{~cm}^{-1}\right)=3066,3019,1617,1584,1044,951,841$, $814,793,691,554,476$. MS (MALDI-TOF) $\mathrm{C}_{36} \mathrm{H}_{24} \mathrm{~S}_{6}$. Calc. 648.97, found $648.363[\mathrm{M}+]$.

TRI-3tph: Yellow solid (88\%). FTIR (KBr): $v\left(\mathrm{~cm}^{-1}\right)=3063,2923,1585$, 1423, 1064, 944, 833, 797, 688, 457 MS (MALDI-TOF) $\mathrm{C}_{48} \mathrm{H}_{30} \mathrm{~S}_{9}$. Calc. 893.98, found $894.165[\mathrm{M}+]$. This material was insufficiently soluble to obtain useful NMR spectra.

DI-3tph: Orange solid (94\%). ${ }^{1} \mathrm{H}$ NMR $\left(600 \mathrm{MHz}, \mathrm{CD}_{3} \mathrm{OD}\right.$, ppm) $\delta: 7.72$ (dd, $J=5.7 \mathrm{~Hz}, 3.3 \mathrm{~Hz}, 2 \mathrm{H}, \mathrm{H}-2$ vinyl), 7.62 (m, 2H, H-1 vinyl), 7.45 (d, $J=$ $3.8 \mathrm{~Hz}, 2 \mathrm{H}, \mathrm{tph}$ ), 7.34 (dd, $J=5.1 \mathrm{~Hz}, 1.1 \mathrm{~Hz}, 2 \mathrm{H}, \mathrm{tph}$ ), 7.25 (dd, J=3.6 Hz, $1.1 \mathrm{~Hz}, 2 \mathrm{H}, \mathrm{tph}), 7.19$ (d, J=3.8 Hz, 2H, tph), 7.14 (m, 4H, tph), 7.05 (dd, $J=5.1 \mathrm{~Hz}, 1.1 \mathrm{~Hz}, 2 \mathrm{H}, \mathrm{tph}) .{ }^{13} \mathrm{C} \mathrm{NMR}\left(600 \mathrm{MHz}, \mathrm{CD}_{3} \mathrm{OD}, \mathrm{ppm}\right) \delta: 143.3$ (C4ํ), $141.2\left(\right.$ C4$\left.^{\circ}\right), 137.9$ (C4º), 132.1 (C-vinyl), 131.4 (tph), 129.6 (C-vinyl), 128.7 (tph), 125.6 (tph), 125.2 (tph), 124.7 (tph), 124.4 (tph). FTIR (KBr): $v\left(\mathrm{~cm}^{-1}\right)=3065,3018,1497,1426,1064,956,833,797,689,528,465$. MS (MALDI-TOF) $\mathrm{C}_{48} \mathrm{H}_{30} \mathrm{~S}_{9}$. Calc. 622.91, found $622.146[\mathrm{M}+]$.

TETRA-3tph: Red solid (92\%). ${ }^{1} \mathrm{H}$ NMR $\left(500 \mathrm{MHz}, \mathrm{CD}_{3} \mathrm{OD}\right.$, ppm) $\delta: 7.56$ (d, $J=3.8 \mathrm{~Hz}, 4 \mathrm{H}$, tph), 7.51 (m, 4H, H-1-vinyl), 7.36 (dd, $J=5.3 \mathrm{~Hz}, 1.4$ $\mathrm{Hz}, 4 \mathrm{H}, \mathrm{tph}), 7.28$ (m, $4 \mathrm{H}, \mathrm{H}-2$ vinyl), 7.26 (dd, $J=3.4 \mathrm{~Hz}, 1.4 \mathrm{~Hz}, 4 \mathrm{H}, \mathrm{tph}$ ), 7.24 (d, $J=3.8 \mathrm{~Hz}, 4 \mathrm{H}, \mathrm{tph}$ ), 7.19 (d, $J=3.8 \mathrm{~Hz}, 4 \mathrm{H}, \mathrm{tph}$ ), 7.16 (d, J=3.8 $\mathrm{Hz}, 4 \mathrm{H}, \mathrm{tph}), 7.13$ (s, 2H, H-Ar), 7.05 (dd, $J=5.3 \mathrm{~Hz}, 3.4 \mathrm{~Hz}, 4 \mathrm{H}, \mathrm{tph}) .{ }^{13} \mathrm{C}$

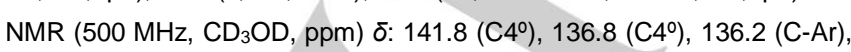
132.6 (tph), 127.9 (tph), 125.3 (tph), 124.9 (tph), 124.4 (tph), 123.9 (tph), 123.6 (tph). FTIR $(\mathrm{KBr}): v\left(\mathrm{~cm}^{-1}\right)=3065,1614,1501,1424,1045,940,837$, 796, 687, 517, 476. MS (MALDI-TOF) $\mathrm{C}_{48} \mathrm{H}_{30} \mathrm{~S}_{9}$. Calc. 1167.61, found $1166.189[\mathrm{M}+]$.

Synthesis of CNHs-DI-3tph, CNHs-TRI-3tph and CNHs-TETRA-3tph: 10 $\mathrm{mg}$ of $p$-CNHs were dispersed in $20 \mathrm{~mL} \mathrm{CHCl} 3$ and $40 \mathrm{mg}$ of DI-3tph, TRI3tph or TETRA-3tph were respectively added to the dispersion and ultrasonicated for $15 \mathrm{~min}$. The resulting dispersion was stirred for $48 \mathrm{~h}$. After that, the crude was filtered on a Millipore Membrane (JGWP $0.2 \mu \mathrm{m}$ ). The black solid collected from the filter was purified by cycles of ultrasonication/filtration in different solvents (odichlorobenzene, $200 \mathrm{~mL}$; $\mathrm{CHCl}_{3}, 100 \mathrm{~mL} ; \mathrm{CH}_{2} \mathrm{Cl}_{2}, 100 \mathrm{~mL}$; and diethyl ether, $50 \mathrm{~mL}$ ). Finally, the product was dried under vacuum obtaining of CNHs-DI-3tph $(14 \mathrm{mg})$, CNHs-TRI-3tph (18mg), and CNHs-TETRA-3tph (22mg).

Fluorescence measurements: Two different solutions were used for every titration. The host solution consisted in a solution of one of the OTV compound at low concentration $\left(\sim 10^{-6} \mathrm{M}\right)$. The guest solution consisted in a solution of the OTV compound (same concentration that the guest solution) plus $p$-CNHs $\left(0.01 \mathrm{mg} \mathrm{mL}^{-1}\right)$. Once the fluorescence of the host solution was measured, increasing amounts of guest solution were added. In this way the concentrations of the OTV were constant during all the experiment avoiding the decrease of the fluorescence due to a dilution effect.

\section{Computational calculations}

All of the computational calculations in this article were obtained using the GAUSSIAN 09 Rev D suites of programs (M. J. Frisch, G. W. Trucks, H. B. Schlegel, G. E. Scuseria, M. A. Robb, J. R. Cheeseman, G. Scalmani, V. Barone, B. Mennucci, G. A. Petersson, H. Nakatsuji, M. Caricato, X. Li, H. P. Hratchian, A. F. Izmaylov, J. Bloino, G. Zheng, J. L. Sonnenberg, M. Hada, M. Ehara, K. Toyota, R. Fukuda, J. Hasegawa, M. Ishida, T. Nakajima, Y. Honda, O. Kitao, H. Nakai, T. Vreven, J. A. Montgomery Jr., J. E. Peralta, F. Ogliaro, M. J. Bearpark, J. J. Heyd, E. N. Brothers, K. N. Kudin, V. N. Staroverov, R. Kobayashi, J. Normand, K. Raghavachari, A. P. Rendell, J. C. Burant, S. S. lyengar, J. Tomasi, M. Cossi, N. Rega, N. J. Millam, M. Klene, J. E. Knox, J. B. Cross, V. Bakken, C. Adamo, J. Jaramillo, R. Gomperts, R. E. Stratmann, O. Yazyev, A. J. Austin, R. Cammi, C. Pomelli, J. W. Ochterski, R. L. Martin, K. Morokuma, V. G. Zakrzewski, G. A. Voth, P. Salvador, J. J. Dannenberg, S. Dapprich, A. D. Daniels, Ö. Farkas, J. B. Foresman, J. V. Ortiz, J. Cioslowski, D. J. Fox Gaussian 09 Revision C.01, Gaussian Inc. : Wallingford CT 2009, 2009.).

The oligothiophenes were optimised using Density Functional Theory (DFT) calculations with the $6-31 \mathrm{G}(\mathrm{d})^{[38]}$ basis set, employing Becke's three parameterised Lee-Yang-Parr exchange functional (B3LYP), ${ }^{[39]}$ Frequency calculations were performed to confirm the nature of the stationary points and to obtain zero-point energies (ZPEs). The frontier molecular orbitals were calculated with $6-31 \mathrm{G}(\mathrm{d})$ using Gaussview to visualizated the topologies.

The model nanohorn employed consisting of 217 carbon atoms, terminated by 19 hydrogen atoms and having a diameter of $13,5 \AA$ at the wide end. The frontier molecular orbitals analysis was performed at b3lyp/6-31G(d) level of theory using Gaussview to visualize the topologies. The optimisation procedure involved a ONION methodology (S. Dapprich, I. Komaromi, K.S. Byun, K. Morokuma, M.J. Frisch, J. Mol. Struct. (Theochem.) 461-462 (1999) 1. ) at B97D/6-31G(d):PM6 level of theory with final refinement at the B97D3BJ/6-31G(d,p) level of theory. The TDDFT calculation were obtained from the optimised structure at m06$2 X / 6-311+G(2 d, 2 p) / / m 06-2 X / 6-31 G(d)$ level of theory. 


\section{Acknowledgements}

Financial support from the MINECO of Spain (projects CTQ201453600-R), Junta de Comunidades de Castilla-La Mancha (project PEII-2014-002-A) and Iberdrola Foundation (CONV120313). Moreover, the technical support from High Performance Computing Service of University of Castilla-La Mancha is gratefully acknowledged MVG thanks Ministerio de Economia y Competitividad for participation in the Ramon y Cajal program.

Keywords: carbon nanomaterials, carbon nanohorns, solar cells, oligothiophenes, non covalent interactions

[1] K. S. Novoselov, A. K. Geim, S. V. Morozov, D. Jiang, Y. Zhang, S. V. Dubonos, I. V. Grigorieva and A. A. Firsov, Science 2004, 306, 666-669.

[2] S. lijima, Nature 1991, 354, 56-58.

[3] S. lijima, M. Yudasaka, R. Yamada, S. Bandow, K. Suenaga, F. Kokai and K. Takahashi, Chem. Phys. Lett. 1999, 309, 165-170.

[4] a) A. Ito and K. Tanaka in Chapter 11 - Applications of Carbon Nanotubes and Graphene in Spin Electronics, (Ed. K. T. lijima), Elsevier, Oxford, 2014, pp. 253-278; b) Z. J. Han, A. E. Rider, C. Fisher, T. van der Laan, S. Kumar, I. Levchenko and K. Ostrikov in Chapter 12 - Biological Application of Carbon Nanotubes and Graphene, (Ed. K. T. lijima), Elsevier, Oxford, 2014, pp. 279-312; c) C.-F. Sun, B. Meany and Y. Wang in Chapter 13 - Characteristics and Applications of Carbon Nanotubes with Different Numbers of Walls, (Ed. K. T. lijima), Elsevier, Oxford, 2014, pp. 313-339; d) C. J. Shearer, A. Cherevan and D. Eder in Chapter 16 - Application of Functional Hybrids Incorporating Carbon Nanotubes or Graphene, (Ed. K. T. lijima), Elsevier, Oxford, 2014, pp. 387-433.

[5] J. Guerra, M. Antonia Herrero, B. Carrion, F. C. Perez-Martinez, M. Lucio, N. Rubio, M. Meneghetti, M. Prato, V. Cena and E. Vazquez, Carbon 2012, 50, 2832-2844.

[6] a) S. Zhu and G. Xu, Nanoscale 2010, 2, 2538-2549; b) G. Pagona, A. S. D. Sandanayaka, T. Hasobe, G. Charalambidis, A. G. Coutsolelos, M. Yudasaka, S. lijima and N. Tagmatarchis, J. Phys. Chem. C 2008, 112, 15735-15741.

[7] a) R. D. Costa, S. Feihl, A. Kahnt, S. Gambhir, D. L. Officer, G. G. Wallace, M. I. Lucio, M. A. Herrero, E. Vzquez, Z. Syrgiannis, M. Prato and D. M. Guldi, Adv. Mater. 2013, 25, 6513-6518; b) R. Casillas, F. Lodermeyer, R. D. Costa, M. Prato and D. M. Guldi, Adv. Energy Mater. 2014, 4, n/a-n/a.

[8] M. Vizuete, M. J. Gómez-Escalonilla, J. L. G. Fierro, A. S. D. Sandanayaka, T. Hasobe, M. Yudasaka, S. lijima, O. Ito and F. Langa, Chem. - Eur. J. 2010, 16, 10752-10763.

[9] G. Pagona, G. E. Zervaki, A. S. D. Sandanayaka, O. Ito, G. Charalambidis, T. Hasobe, A. G. Coutsolelos and N. Tagmatarchis, J. Phys. Chem. C 2012, 116, 9439-9449.

[10] M. Melchionna and M. Prato, Ecs J. Sol. Sci. Technol. 2013, 2, M3040-M3045.

[11] a) S.-C. Lo and P. L. Burn, Chem. Rev. 2007, 107, 1097-1116; b) P. L. Burn, S.-C. Lo and I. D. W. Samuel, Adv. Mater. 2007, 19, 16751688; c) J. Roncali, P. Leriche and A. Cravino, Adv. Mater. 2007, 19, 2045-2060.
[12] a) S. A. Ponomarenko, S. Kirchmeyer, A. Elschner, B. H. Huisman, A. Karbach and D. Drechsler, Adv. Funct. Mater. 2003, 13, 591-596; b) W. J. Mitchell, N. Kopidakis, G. Rumbles, D. S. Ginley and S. E. Shaheen, J. Mater. Chem. 2005, 15, 4518-4528; c) H. John, R. Bauer, P. Espindola, P. Sonar, J. Heinze and K. Mullen, Angew. Chem. Int. Edit. 2005, 44, 2447-2451; d) Y. Zhang, C. Zhao, J. Yang, M. Kapiamba, O. Haze, L. J. Rothberg and M.-K. Ng, J. Org. Chem. 2006, 71, 9475-9483; e) N. Negishi, Y. le, M. Taniguchi, T. Kawai, H. Tada, T. Kaneda and Y. Aso, Org. Lett. 2007, 9, 829-832; f) W. J. Mitchell, A. J. Ferguson, M. E. Köse, B. L. Rupert, D. S. Ginley, G. Rumbles, S. E. Shaheen and N. Kopidakis, Chem. Mater. 2009, 21, 287-297; g) M. K. R. Fischer, T. E. Kaiser, F. Wurthner and P. Bauerle, J. Mater. Chem. 2009, 19, 1129-1141; h) M. E. Köse, H. Long, K. Kim P. Graf and D. Ginley, J. Phys. Chem. A 2010, 114, 4388-4393; i) W. W. H. Wong, C.-Q. Ma, W. Pisula, C. Yan, X. Feng, D. J. Jones, K. Müllen, R. A. J. Janssen, P. Bäuerle and A. B. Holmes, Chem. Mater. 2010, 22, 457-466; j) S. Deng, G. Krueger, P. Taranekar, S. Sriwichai, R. Zong, R. P. Thummel and R. C. Advincula, Chem. Mater. 2011, 23, 3302-3311; k) R. Ponnapati, M. J. Felipe and R. Advincula, Macromolecules 2011, 44, 7530-7537.

[13] a) J. Roncali, Chem. Rev. 1997, 97, 173-205; b) D. Fichou and C. Ziegler in Structure and Properties of Oligothiophenes in the Solid State: Single Crystals and Thin Films, Wiley-VCH Verlag GmbH, 2007, pp. 183-282.

[14] C. Hadad, J. C. Garcia-Martinez and J. Rodriguez-Lopez, J. Org. Chem. 2012, 77, 6223-6230.

[15] J.-L. Wang, C. Zhong, Z.-M. Tang, H. Wu, Y. Ma, Y. Cao and J. Pei, Chem-Asian J. 2010, 5, 105-113.

[16] A. Mishra and P. Baeuerle, Angew. Chem. Int. Edit. 2012, 51, 2020-2067.

[17] A. Mishra, C.-Q. Ma and P. Baeuerle, Chem. Rev. 2009, 109, 1141-1276.

[18] D. Iglesias, P. Atienzar, E. Vazquez, M. Antonia Herrero, H. Garcia, Carbon 2016, in preparation.

[19] a) P. R. L. Malenfant, L. Groenendaal and J. M. J. Frechet, J. Am. Chem. Soc. 1998, 120, 10990-10991; b) K. H. Kim, Z. Chi, M. J. Cho J.-I. Jin, M. Y. Cho, S. J. Kim, J.-s. Joo and D. H. Choi, Synthetic Met. 2007, 157, 497-501; c) P. Mayorga Burrezo, B. Pelado, R. Ponce Ortiz, P. De la Cruz, J. T. López Navarrete, F. Langa and J. Casado, Chem. - Eur. J. 2015, 21, 1713-1725; d) C. O. Sanchez, P. Sobarzo and N. Gatica, New J. Chem. 2015, 39, 7979-7987.

[20] a) F. Moggia, C. Videlot-Ackermann, J. Ackermann, P. Raynal, H Brisset and F. Fages, J. Mater. Chem. 2006, 16, 2380-2386; b) C Videlot-Ackermann, J. Ackermann, H. Brisset, K. Kawamura, N. Yoshimoto, P. Raynal, A. El Kassmi and F. Fages, J. Am. Chem. Soc. 2005, 127, 16346-16347.

[21] a) A. Klamt and G. Schuurmann, J. Chem. Soc., Perk. T 21993 , 799-805; b) J. Andzelm, C. Kolmel and A. Klamt, J. Chem. Phys. 1995, 103, 9312-9320; c) V. Barone and M. Cossi, J. Phys. Chem. A 1998, 102, 1995-2001; d) M. Cossi, N. Rega, G. Scalmani and V. Barone, J. Comput. Chem. 2003, 24, 669-681.

[22] C. Adamo and D. Jacquemin, Chem. Soc. Rev. 2013, 42, 845856.

[23] Y. Zhao and D. G. Truhlar, Theor. Chem. Acc. 2008, 120, 215241.

[24] J. Luo, H. Qu, J. Yin, X. Zhang, K.-W. Huang and C. Chi, J. Mater. Chem. 2009, 19, 8202-8211.

[25] J. Muñiz, E. Sansores, A. Olea and E. Valenzuela, Int. J. Quantum Chem. 2013, 113, 1034-1046. 
[26] S. Laref, A. M. Asaduzzaman, W. Beck, P. A. Deymier, K. Runge, L. Adamowicz and K. Muralidharan, Chemical Physics Letters 2013, $582,115-118$.

[27] a) I. D. Petsalakis, G. Pagona, N. Tagmatarchis and G. Theodorakopoulos, Chem. Phys. Lett. 2007, 448, 115-120; b) I. D. Petsalakis, G. Pagona, G. Theodorakopoulos, N. Tagmatarchis, M. Yudasaka and S. lijima, Chem. Phys. Lett. 2006, 429, 194-198.

[28] a) S. Grimme, J. Antony, S. Ehrlich and H. Krieg, J. Chem. Phys. 2010, 132, 154104; b) S. Grimme, S. Ehrlich and L. Goerigk, J. Comput. Chem. 2011, 32, 1456-1465.

[29] R. M. Shields, B. Temelso, K. A. Archer, T. E. Morrell and G. C. Shields, J. Phys. Chem. A 2010, 114, 11725-11737.

[30] B. C. Thompson and J. M. J. Frechet, Angew. Chem. Int. Edit. 2008, 47, 58-77.

[31] L. Xie, X. Ling, Y. Fang, J. Zhang and Z. Liu, J. Am. Chem. Soc 2009, 131, 9890-9891.

[32] X. Ling, L. Xie, Y. Fang, H. Xu, H. Zhang, J. Kong, M. S. Dresselhaus, J. Zhang and Z. Liu, Nano Lett. 2010, 10, 553-561.

[33] a) W. Xu, X. Ling, J. Xiao, M. S. Dresselhaus, J. Kong, H. Xu, Z. Liu and J. Zhang, P. Natl. A. Sci. 2012, 109, 9281-9286; b) W. Xu, N. Mao and J. Zhang, Small 2013, 9, 1206-1224.

[34] a) N. Ramos-Berdullas, D. Lopez-Carballeira, I. Perez-Juste and M. Mandado, J. Raman Spectrosc. 2015, 46, 1205-1214; b) R. L. McCreery in Raman Spectroscopy of Surfaces, John Wiley \& Sons, Inc., 2005, pp. 373-413; c) J. Zhao and R. L. McCreery, Langmuir 1995, 11, 4036-4040; d) M. R. Kagan and R. L. McCreery, Langmuir 1995, 11, 4041-4047.

[35] R. L. McCreery, Raman Spectroscopy for Chemical Analysis, 2000, p.

[36] a) T. Murakami, J. Fan, M. Yudasaka, S. lijima and K. Shiba, Mol. pharm. 2006, 3, 407-414; b) G. Mountrichas, T. Ichihashi, S. Pispas, M. Yudasaka, S. lijima and N. Tagmatarchis, J. Phys. Chem. C 2009, $113,5444-5449$.

[37] P. Styles, N. F. Soffe, C. A. Scott, D. A. Cragg, F. Row, D. J. White and P. C. J. White, J. Magn. Reson. 1984, 60, 397-404.

[38] a) R. Ditchfie, W. J. Hehre and J. A. Pople, J. Chem. Phys. 1971, 54, 724; b) W. J. Hehre, R. Ditchfie and J. A. Pople, J. Chem. Phys. 1972, 56, 2257; c) Harihara.Pc and J. A. Pople, Theor. Chim. Acta 1973, 28, 213-222; d) P. C. Hariharan and J. A. Pople, Mol. Phy. 1974, 27, $209-214$.

[39] a) C. Lee, W. Yang and R. G. Parr, Phys. Rev. B 1988, 37, 785789; b) A. D. Becke, J. Chem. Phys. 1993, 98, 5648-5652. 
Entry for the Table of Contents (Please choose one layout)

Layout 1:

\section{FULL PAPER}

Carbon nanohorns have been decorated with polyconjugated molecules based on thiophene derivatives. These systems show promising properties for the design of: 1) more effective and versatile solar cells devices and 2) new platforms for Raman enhancement without any metal on the surface. Aiming at a comprehensive understanding of these properties, the hybrids were fully analysed by different characterization techniques and computational studies.
Daniel Iglesias, Javier Guerra, M. Victoria Gómez, Antonio M. Rodríguez, Pilar Prieto, Ester Vázquez, M. Antonia Herrero*

Page No. - Page No.

Design of Assembled Systems

Based on Conjugated

Polyphenylene Derivatives and

Carbon Nanohorns

Layout 2:

\section{FULL PAPER}

Author(s), Corresponding Author(s)*

Page No. - Page No.

Title 